\title{
O ACOLHIMENTO INSTITUCIONAL NA PERSPECTIVA DOS TRABALHADORES DOS SERVIÇOS DE PROTEÇÃO: MÚLTIPLOS SENTIDOS
}

INSTITUTIONAL WELFARE IN THE PERSPECTIVE OF PROTECTION SERVICE WORKERS: MULTIPLE SENSES

\section{LA ACOGIDA INSTITUCIONAL EN LA PERSPECTIVA DE LOS TRABAJADORES DE LOS SERVICIOS DE PROTECCIÓN: MÚLTIPLES SENTIDOS}

\author{
Júnia Aparecida Ferreira* \\ Maria Ignez Costa Moreira ${ }^{* *}$
}

\begin{abstract}
RESUMO
Este artigo é fruto da dissertação "As políticas de proteção à criança e ao adolescente no Município de Belo Horizonte: o contexto do acolhimento institucional" (2016), que foi elaborada como uma pesquisa qualitativa com o objetivo de conhecer, por meio da triangulação de estratégias metodológicas, as práticas e as narrativas sobre o acolhimento institucional destinadas às crianças e aos adolescentes, na perspectiva dos gestores da política pública e dos trabalhadores das casas de acolhimento institucional. Foi tomado como guia metodológico o construcionismo social, que compreende o conhecimento como socialmente construído. O estudo das narrativas que emergem dos documentos e das entrevistas realizadas com os trabalhadores da política de Assistência Social apontou que as açóes de atendimento às crianças, adolescentes e suas famílias são constituídas em um cenário complexo e dinâmico, e entre a prescrição legal e a prática cotidiana são produzidas contradições, reproduções e transformações dos sentidos do acolhimento institucional.
\end{abstract}

Palavras-chaves: Acolhimento institucional. Estatuto da Criança e do Adolescente. Construcionismo social. Práticas discursivas. Produção de sentido.

\section{ABSTRACT}

This article is the result of the dissertation "Policies for the Protection of Children and Adolescents in the Municipality of Belo Horizonte: the Context of Institutional Reception" (2016), which was elaborated as a qualitative research with the objective of knowing, through the

\footnotetext{
Texto recebido em 2 maio de 2016 e aprovado para publicação em 18 de dezembro de 2016.

* Mestre em Psicologia, Programa de Pós-Graduação em Psicologia da PUC Minas. E-mail: juniaaf@yahoo.com.br.

** Doutora em Psicologia Social pela PUC SP, professora no Programa de Pós-Graduação em Psicologia da PUC Minas. E-mail: maigcomo@uol.com.br.
} 
triangulation of Methodological strategies, practices and narratives on the institutional reception for children and adolescents, from the perspective of public policy managers and workers in institutional shelters. It was taken as methodological guide social constructionism, which comprises knowledge as socially constructed. The study of the narratives that emerge from the documents and the interviews with the workers of the social assistance policy pointed out that the actions of care for children, adolescents and their families are constituted in a complex and dynamic scenario, and between legal prescription and practice contradictions, reproductions and transformations of the meanings of institutional.

Keywords: Institutional reception. Statute of the Child and Adolescent. Social constructionism. Discursive practices. Production of sense.

\section{RESUMEN}

Este artículo es el resultado de la disertación "Las políticas de protección al niño y al adolescente en la ciudad de Belo Horizonte: el contexto del acogimiento institucional" (2016), que fue elaborada como una investigación cualitativa con el fin de conocer, a través de triangulación de estrategias metodológicas, prácticas y narrativas sobre el acogimiento institucional para los niños y adolescentes, desde la perspectiva de los gestores de las políticas públicas y de los trabajadores de las casas de acogimiento institucional. Fue tomada como una guía metodológica el construccionismo social, que comprende el conocimiento como algo socialmente construido. El estudio de las narrativas que surgen de los documentos y entrevistas realizadas con los trabajadores de la política de bienestar social señaló que las acciones de atención a niños, adolescentes y sus familias están constituidas en un escenario complejo y dinámico, y entre la prescripción legal y la práctica cotidiana se producen contradicciones, reproducciones y transformaciones de los sentidos del acogimiento institucional.

Palabras clave: Acogimiento institucional. Estatuto del Niño y del Adolescente. Construccionismo social. Prácticas discursivas. Producción de sentido.

\section{O TRAÇADO METODOLÓGICO DA PESQUISA}

ste artigo é derivado da dissertação de mestrado "As políticas de proteção
à criança e ao adolescente no Município de Belo Horizonte: o contexto
do acolhimento institucional" (Programa de Pós-graduação em Psicologia
da PUC Minas, 2016). A dissertação foi desenvolvida de modo integrado
à participação da autora no projeto de pesquisa "Formação e capacitação de
equipes de trabalho para as entidades de acolhimento institucional para crianças 
e adolescentes: produção de inovações metodológicas" (Fundação de Amparo a Pesquisa de Minas Gerais [Fapemig], 2014-2016).

Com o objetivo de compreender as narrativas produzidas pelos operadores da medida protetiva de acolhimento institucional, buscou-se a triangulação das seguintes estratégias metodológicas: levantamento bibliográfico; análise documental; diário de campo produzido durante a participação da pesquisadora no "Ciclo de debates sobre a medida de acolhimento institucional em Belo Horizonte e revisão da resolução 31/97" (novembro de 2014 e janeiro de 2015); aplicação de um questionário aos trabalhadores das casas de acolhimento institucional; entrevistas semiestruturadas com os gestores da política pública municipal de Assistência e os trabalhadores das casas de acolhimento institucional; e realização de oficinas temáticas com os trabalhadores das unidades de acolhimento.

A articulação de estratégias metodológicas foi definida por Minayo (2005) como triangulação, que, segundo a autora, permite compreender contextos complexos, tais como os da medida de acolhimento institucional. As aproximações de diversas estratégias, cada uma com sua natureza e especificidade, devem ser manejadas pelos pesquisadores de modo complementar e na rigorosa observação dos requisitos de cada uma delas.

Neste artigo, serão apresentadas as análises das narrativas sobre o acolhimento institucional produzidas a partir de duas estratégias metodológicas: a pesquisa documental, que compreendeu a análise dos documentos que orientam as políticas públicas de proteção à infância e adolescência no Brasil, e as entrevistas semiestruturadas realizadas com os gestores municipais da política de Assistência Social e com os trabalhadores das casas de acolhimento institucional.

O objetivo da articulação dessas duas estratégias metodológicas foi o de compreender as apropriações e interpretaçôes realizadas pelos atores responsáveis pela prática da medida de acolhimento institucional, tanto no nível da elaboração e gestão da política quanto de sua execução ao público a que ela se destina. A compreensão das narrativas oficiais registradas nos documentos e das narrativas dos gestores e trabalhadores entrevistados revelou não apenas os hiatos e as diferenças entre o prescrito e o vivido, mas também os conflitos e as potencialidades de transformação da prática cotidiana de aplicação da medida protetiva de acolhimento institucional e como tais práticas reverberam no aprimoramento dos documentos normativos.

Entre as diversas ações que concretizam as políticas de Assistência Social dirigidas às crianças e aos adolescentes está a medida protetiva de acolhimento institucional, destinada às crianças e aos adolescentes em situação de violência e de violação de seus direitos. Essa medida é normatizada especialmente pelos 
seguintes documentos: o Estatuto da Criança e do Adolescente (ECA) (Lei n. ${ }^{\circ}$ 8.069, 1990), o Plano Nacional de Promoção, Proteção e Defesa do Direito à Convivência Familiar e Comunitária (Brasil, 2006) e a Lei no 12.010 , de 3 de agosto de 2009. Esses documentos foram analisados com o objetivo de conhecermos os aspectos prescritos da política pública de Assistência Social destinada a crianças e adolescentes e suas famílias. Em seguida, foram realizadas entrevistas semiestruturadas com os gestores da política pública municipal de Assistência Social e do Conselho Municipal de Direitos da Criança e do Adolescente (CMDCA), bem como com os trabalhadores inseridos nas casas de acolhimento institucional, em Belo Horizonte.

Foram entrevistados 12 sujeitos: gestores, identificados a partir do contato com o CMDCA e com a gerência de abrigamento da Prefeitura Municipal de Belo Horizonte; trabalhadores das casas de acolhimento institucional, selecionados com base na análise dos dados coletados em um questionário previamente aplicado. As entrevistas foram gravadas e transcritas para o desenvolvimento das análises, por meio das quais se buscou compreender os sentidos construídos pelos diversos atores do acolhimento institucional (gestores públicos, coordenadores, técnicos e educadores das próprias casas de acolhimento) para o cotidiano de trabalho. Como veremos, na voz de cada um, muitas vozes reverberam.

No estudo dos documentos, trabalhamos com a concepção de Cellard (2010), para quem esses textos devem ser explorados e analisados com base na identificação do contexto histórico e social de sua produção bem como do contexto dos sujeitos a quem os documentos são endereçados.

As narrativas encontradas nos documentos oficiais e aquelas produzidas nas entrevistas foram sistematizadas inicialmente em quatro categorias:

a) a medida de acolhimento institucional: das normativas ao cotidiano dos serviços de proteção;

b) a relação entre as entidades de acolhimento institucional e o município de Belo Horizonte;

c) as crianças, os adolescentes e suas famílias: avanços e permanências nas concepçôes do atendimento;

d) o sistema de garantia de direito e o trabalho em rede.

No entanto, durante as sucessivas leituras das transcrições das entrevistas, outra categoria foi criada com base nas narrativas dos trabalhadores: "A gente age naturalmente" e "É preciso fazer a diferença": essas expressões utilizadas pelos 
profissionais revelaram sentidos construídos na prática cotidiana de atendimento às crianças e aos adolescentes.

\section{A LENTE DO CONSTRUCIONISMO SOCIAL}

Ao longo da pesquisa realizada para a elaboração da dissertação, deparamo-nos com as múltiplas dimensões da medida protetiva de acolhimento institucional, significada e ressignificada na organização e no cotidiano dos serviços de atendimento às crianças, aos adolescentes e suas famílias. Convidados a falar sobre a medida protetiva, os profissionais revelaram a diversidade dos sentidos construídos. Tal diversidade guarda profunda relação com o contexto no qual o discurso é produzido e com a visão de mundo desses profissionais, como nos ensina a perspectiva metodológica do construcionismo social.

O universo do estudo contemplou a participação de profissionais vinculados a diferentes equipamentos do chamado sistema de garantia de direitos:

a) gestores e supervisores da Secretaria Municipal Adjunta de Assistência Social, responsáveis pelas ações de planejamento, no âmbito da política pública de Assistência Social, pela implantação das ações de atendimento às crianças e aos adolescentes, bem como pelo monitoramento e acompanhamento das ações, o que implica a realização dos estudos de caso e da supervisão das entidades conveniadas;

b) representante do CMDCA, que, na relação com o poder público e com a sociedade, tem o papel de discutir a constituição da Política Pública Municipal de Atendimento às Crianças e aos Adolescentes e realizar o controle de sua execução; e

c) os educadores, técnicos e coordenadores inseridos nas casas de acolhimento, que prestam o serviço de atendimento direto a crianças, adolescentes e famílias.

As narrativas desses profissionais sobre a medida protetiva de acolhimento institucional e suas experiências no trabalho cotidiano transitam entre os elementos prescritos na legislação, reproduzidos em sua essência, uma vez que se espera deles domínio do conteúdo desses documentos, que deveriam ser tomados como guias na execução das açóes cotidianas. No entanto, as narrativas desses profissionais mostram que as açóes propriamente ditas, realizadas em contextos específicos e particulares, exigem deles, não raras vezes, adequações e adaptações das prescriçōes das normativas. 
O trabalho no campo do acolhimento, ou seja, da sétima medida protetiva determinada pelo ECA (Lei n. ${ }^{\circ} 8.069,1990$ ), ocorre em um cenário complexo, no qual se encontram e se desencontram diversos equipamentos e instituições sociais, sujeitos em diversas posiçôes sociais, profissionais da Assistência Social, operadores do sistema jurídico, crianças, adolescentes e suas famílias, tudo isso concorre para uma polifonia de vozes. Considerando que o estudo realizado buscou a compreensão dos sentidos construídos pelos profissionais, tomando como referência o construcionismo social, pode-se dizer que a complexidade apresentada resulta num processo em que o ECA (Lei n. ${ }^{\circ}$ 8.069, 1990) e as demais normativas no campo da proteção, bem como os princípios aí estabelecidos são significados e apreendidos pelas instituiçōes e pelos profissionais e transformados em ações cotidianas. Apreensão que é mediada pela filosofia e pelos princípios institucionais e também pelos valores e crenças subjetivas dos profissionais.

Os discursos produzidos pelos diversos profissionais foram acessados em diferentes lugares e por diferentes estratégias, o que contribuiu para múltiplas perspectivas de interação entre a pesquisadora e os sujeitos, por exemplo, na realização de uma entrevista com uma gestora da política pública de assistência, inicialmente planejada como uma entrevista individual, mas que acabou convertida em uma entrevista com duas gestoras, em uma sala de um equipamento municipal, por iniciativa das próprias gestoras.

As teses do construcionismo social sustentam que a posição do pesquisador é comprometida de forma política, ética e afetiva. O construcionismo social nos ensina que é na qualidade da interação social que o pesquisador estabelece com os sujeitos inseridos no seu campo de estudos, no caso deste estudo, a prática da medida de acolhimento institucional, que o conhecimento poderá ser produzido.

Os sentidos para o acolhimento institucional são construídos pelos múltiplos envolvidos, ou seja, tanto pelos que formularam os arcabouços jurídicos e instituições quanto pelos gestores e trabalhadores das casas de acolhimento e pelas famílias, suas crianças e seus adolescentes, destinatários da medida. O construcionismo social tem como pressuposto que a construção compartilhada da realidade é um processo que acontece de maneira coletiva e com elementos diversos (Gergen \& Gergen, 2010; Iñiguez, 2002; Spink, 2013). Com base nessa chave de leitura, entende-se que a política de proteção é também de autoria coletiva e conta com a participação de trabalhadores, das instituições e dos beneficiários dos serviços de atendimento, que ocupam posições diferentes nesse contexto. Evidentemente, tal cenário pressupõe dissensos, negociações e a produção de alguns consensos, num contexto de conflitos e de exercício de poder. 
Para o construcionismo social, somos, ao mesmo tempo, produtos e produtores de nossa história: "Construímos o mundo de forma diferente e essa diferença encontra-se enraizada em nossas relações sociais, a partir das quais o mundo se tornou o que é" (Gergen \& Gergen, 2010, p. 19).

Gergen (2009) considera que os estudos construcionistas tratam do cotidiano e da maneira como as pessoas falam, percebem e experimentam o mundo em que vivem e os processos de interação entre as pessoas e seus contextos. Portanto, para esse autor, deve-se considerar a relação entre as pessoas para que se possa compreender os sentidos produzidos.

Na perspectiva construcionista, como nos lembra Iñiguez (2002), a linguagem é uma ação: "Falar equivale a uma ação sobre o mundo" (p. 136). A concepção aqui presente é que a linguagem, compreendida como ação coletiva, permite a elaboração de sentidos. Todo o contexto do acolhimento e da política de proteção à criança e ao adolescente é circunscrito pelas diferentes concepçôes sobre quem são as crianças e os adolescentes que chegam ao acolhimento institucional, quem são suas famílias, o que são direitos e o que se constitui como violação destes e, por último, mas não menos importante, quais são as ações de atendimento que se espera sejam construídas.

$\mathrm{Na}$ perspectiva construcionista social, deve-se abordar a verdade como uma produção dinâmica e não como um fato estático, ou seja, a verdade é datada e histórica, tem as marcas das instituições, das relações e das convenções sociais. No caso específico deste estudo, têm-se as construções sociais sobre o acolhimento de crianças e adolescentes e as ações cotidianas, muitas vezes associadas às práticas assistencialistas e correcionais desenvolvidas nos contextos marcados por concepções de criança, de adolescente e de família presentes do Código de Menores (Decreto n. ${ }^{\circ}$ 17.943-A, 1927; Lei n. ${ }^{\circ} 6.697,1979$ ), portanto anteriores ao ECA (Lei n. ${ }^{\circ} 8.069$, 1990), ao lado da consideração das concepções veiculadas pelo ECA. Essas duas "verdades" antagônicas acabam por engendrar uma outra "verdade", a dos sentidos produzidos por todos os envolvidos no cotidiano do acolhimento institucional.

Outro conceito utilizado na análise do material produzido foi o de práticas discursivas, discutido por Spink (2013) e Mello (2002), que nos possibilitam compreendê-las como ações realizadas por sujeitos ativos que interagem em contextos específicos, nos quais desenvolvem relações de poder, de enfrentamento e de negociação.

Mello (2002) considera ainda que "as práticas discursivas se revelam como estratégias de poderes: como ordenamentos crescentes em todas as esferas da vida, para agenciar novas formas do existir humano ou perpetuá-las" (p. 60). 
O contexto do acolhimento é marcado por relações de poder distintas, assimétricas e desiguais, estabelecidas entre as instituições e seus trabalhadores. As práticas de atendimento à criança e ao adolescente resultam dessas relações, ao mesmo tempo em que, por meio de negociações constantes à luz dos princípios prescritos na legislação, e com os diversos operadores do sistema de garantia de direitos, produzem modos e saberes que norteiam as açôes cotidianas desenvolvidas nos serviços. Negociação que se dá no contexto de um serviço que compõe uma política pública, mas que é atravessado pela filosofia das instituições sociais, em grande parte filiadas a associações religiosas, e que são responsáveis pela execução da medida de acolhimento institucional.

\section{AS NORMATIVAS E AS PRÁTICAS COTIDIANAS: SENTIDOS CONSTRUÍDOS PELOS PROFISSIONAIS NO DESENVOLVIMENTO DAS AÇÕES}

Ao relatarem o cotidiano dos serviços, os trabalhadores apresentam as próprias concepções sobre a medida de acolhimento bem como as concepções que acreditam que as outras instituições do sistema de garantia de direitos, as famílias, as crianças e os adolescentes têm sobre a medida. Desse modo, encontramos na narrativa de cada sujeito entrevistado os ecos das narrativas de todos os outros sujeitos implicados na medida de acolhimento institucional. Vejamos:

Eu também acho que as entidades não têm essa segurança para oferecer esses serviços alternativos, porque quem faz esses serviços são entidades que têm determinadas é [...] Vamos dizer princípios, determinados princípios, às vezes religiosos, às vezes [...] Então elas são muito ligadas a uma outra noção de acolhimento, né? Um acolhimento no sentido da palavra do acolher mesmo desse cuidado mais é [...] solidário [...] mais caridoso [...] Então, se pensar em alternativas para esse modelo, né, eu acho complicado. Então se teria que ter novos modelos mesmo. Tem que ter esses, também, não estou dizendo que tenha, o problema é só ter esses e não ter os outros (Representante do CMDCA).

$\mathrm{Na}$ fala da representante do CMDCA, o acolhimento institucional é associado à dimensão da solidariedade e da caridade. Esta que se contrapõe à perspectiva de um atendimento definido nos documentos legais e nos ordenamentos de política pública como tendo a função de garantia de direitos, dos quais são portadores todas as crianças e todos os adolescentes. Tomando como guia o construcionismo social, vale lembrar que as casas de acolhimento que atendem crianças e adolescentes, conveniadas com o Município de Belo Horizonte, em sua maioria, são filiadas a entidades religiosas. Nesse contexto, o sentido caritativo de prover as crianças e os adolescentes de recursos materiais e simbólicos para suprir as suas necessidades está relacionado a um ato de benevolência para com 
eles. O sentido do acolhimento como um direito universal e não condicionado deixa de ser considerado, o que acarreta, muitas vezes, processos que envolvem a submissão das crianças e dos adolescentes aos ritos dessas religiōes, e que não promovem a autonomia e a cidadania dos acolhidos. Situação expressa no trecho que segue:

A gente tem entidades aqui, por exemplo, que os meninos não podem tomar café porque é da Igreja Adventista e Adventistas não tomam café, não tomam cafeína, é [...] Você é adventista, o menino não é! [...] Porque o serviço, ele não é executado de maneira isenta, vamos dizer assim. Você tem entidades de acolhimento em que o menino é obrigado a ir à missa todo domingo. E se o menino não for católico, se o menino não tiver religião? (Supervisora de unidade de acolhimento).

Tradicionalmente, no Brasil, os serviços de assistência às pessoas em situação de vulnerabilidade social eram realizados por tais entidades, que deviam atender às diretrizes religiosas de suas mantenedoras. No entanto, após a promulgação do ECA, as diretrizes são postas pela lei, e as entidades consideradas parceiras e executoras da medida de acolhimento institucional devem se conduzir tendo como referência os princípios constitucionais do Estado brasileiro, declarado laico em sua Carta Magna. Tem-se, assim, a constituição de uma política pública atravessada pelo lugar que tais instituiçóes ocupam socialmente.

Alçada à condição de política pública, a Assistência Social passa a ser de responsabilidade do Estado, mas tal responsabilidade é compartilhada com a sociedade civil. Atualmente, os serviços que integram as mais diversas políticas de Assistência Social, em sua grande maioria, permanecem sendo executados pelas instituiçôes sociais, as chamadas Organizações da Sociedade Civil de Interesse Público Social (OSCIP).

Ao iniciarem a prestação de serviços, no âmbito do acolhimento institucional, as entidades nem sempre têm a expertise demandada pelo contexto no qual buscam se inserir. Sem uma capacitação prévia, as ações de atendimento construídas ainda são, muitas vezes, guiadas pelas práticas assistencialistas de atenção aos pobres vigentes no Brasil até a promulgação do ECA (Lei n. $\left.{ }^{\circ} 8.069,1990\right)$.

Aí na hora que eles começam a executar e ver que é pepino atrás de pepino, bomba atrás de bomba [...] Aí você pega gente que nunca executou serviço de acolhimento e que tem na cabeça aquele modelo de orfanato, de achar que o acolhimento é análogo ao cumprimento de medida de semiliberdade, de restrição de liberdade. Acha que é isso que o menino tá lá porque ele cometeu algum ato infracional. Tem entidade que pensa assim, que o menino tá lá pra ser castigado, não no sentido de que o menino sofre castigo, mas a visão de que o menino tá lá pra ser "educado", como se fosse um reformatório (Supervisor de unidade de acolhimento). 
$\mathrm{Na}$ narrativa desse profissional, o acolhimento aparece associado a um contexto de complexidade, marcado pelos conflitos e pela diversidade de situações-problemas. As expressões "pepino atrás de pepino" e "bomba atrás de bomba" remetem à complexidade das demandas e à imprevisibilidade dessas. Como "pepino" pode-se entender que um acolhimento é de difícil digestão e aceitação no contexto das famílias. Por outro lado, as histórias que chegam às casas de acolhimento, os motivos que justificaram a aplicação da medida podem, também, revelar conteúdos indigestos para as equipes das unidades, como os casos de abuso sexual e de maus-tratos sofridos pelas crianças, especialmente em seus primeiros anos de vida.

A imprevisibilidade, por sua vez, contida na expressão "bomba atrás de bomba" remete à diversidade e à complexidade das demandas. As histórias das crianças, dos adolescentes e suas famílias são singulares e complexas. Portanto demandas distintas são colocadas às instituições e à rede de atendimento. A bomba carrega consigo uma ameaça que remete a risco de destruição do que está estabelecido e da ordem desejada, de modo que a imprevisibilidade deve ser combatida e as bombas desativadas.

$\mathrm{Na}$ fala acima, a medida protetiva de acolhimento institucional é associada à medida socioeducativa de restrição de liberdade, ou seja, ao castigo e à "educação repressiva". Nesse contexto, o atendimento seria uma forma de punição da criança e do adolescente, o que se configura como uma distorção da finalidade da sétima medida protetiva, que visa à proteção e à garantia de direitos. A restrição de liberdade, prevista no ECA (Lei n. $\left.{ }^{\circ} 8.069,1990\right)$, está no âmbito da medida socioeducativa. Da mesma forma, o castigo e a "educação" como sinônimos de intervenção para prevenir ou recuperar os adolescentes que cometeram um ato infracional são tomados exclusivamente como medida punitiva, como se aquele que recebesse uma medida socioeducativa estivesse excluído de qualquer direito previsto pelo ECA (Lei n. ${ }^{\circ}$ 8.069, 1990).

Os sentidos acima encontram consonâncias com aqueles atribuídos ao papel das entidades, apresentadas na fala como orfanato e reformatório. $\mathrm{Na}$ história da assistência à infância e à adolescência no Brasil, essas duas instituições foram responsáveis pelo atendimento às crianças e aos adolescentes, atuando no contexto de uma assistência asilar, conforme apontam Rizzini e Rizzini (2004, p. 14):

Várias gerações de crianças passaram suas infância e adolescência internadas em grandes instituições fechadas. Estas eram, até o final da década de 1980, denominadas de "internatos de menores" ou "orfanatos" e funcionavam nos moldes de asilos. 
Com base no construcionismo social, compreende-se que as marcas históricas de um atendimento destinado "aos menores", representados pelos códigos de menores (Decreto n. ${ }^{\circ}$ 17.943-A, 1927; Lei n. ${ }^{\circ}$ 6.697, 1979) como aqueles em "situação irregular" e "delinquentes", permanecem nas novas práticas de atendimento na chamada era da proteção integral instituída pelo ECA, que coloca todas as crianças e adolescentes na condição de sujeitos de direitos.

A existência de tais marcas no desenvolvimento das atuais ações de atendimento pode ser observada nas falas de um profissional supervisor das unidades e de um educador social, quando relatam o trabalho realizado nas instituiçóes de acolhimento:

Aqui ele fica acautelado, mesmo, durante a semana toda. Tanto que as atividades durante a semana é dentro da casa, ou na área externa, mas acompanhado de educadores, nunca eles estão sozinhos (Educador social).

Como que se trabalha com essas entidades? É um trabalho muito de formiga, sabe? É um trabalho muito de dia a dia, tentar sensibilizar as pessoas de que não é isso. Tirar esses resquícios de Febem da cabeça das pessoas [...] (Supervisor de unidade de acolhimento).

$\mathrm{Na}$ perspectiva da linguagem como uma forma de ação sobre o mundo e as pessoas, pode-se dizer que tais concepções se configuram como uma ação sobre as famílias, as crianças e os adolescentes. "Acautelado" e "tirar esses resquícios de Febem" remetem à privação de liberdade bem como à dificuldade de superação da representação do "menor em situação irregular" para a apropriação da condição de crianças e adolescentes como sujeitos de direitos.

A família das crianças e adolescentes, na visão dos profissionais, é despotencializada e considerada incapaz de cuidar de seus filhos, uma família avaliada de modo estanque e sem levar em conta sua história e seus contextos, como relata um dos entrevistados:

O que acontece hoje em dia é que a criança é acolhida, as unidades de acolhimento vão lá, tiram uma foto dessa família, num momento em que a criança é acolhida, e essa foto elas chamam de relatório circunstanciado. Então essa foto ela é remetida ao [...] ao Judiciário, da maneira em que ela foi encontrada. Então eu vou lá e tiro uma foto da família que está totalmente desestruturada, a ponto da criança ser acolhida, e remeto essa foto ao Judiciário e o Judiciário obviamente olha a foto e fala "Oh, gente, que família horrível né, não tem como essa criança voltar pra lá”. É [...] então acho que a gente peca nesse sentido de trabalhar com a família. A gente precisaria dar uma melhorada no cenário antes de tirar essa foto, para poder efetivamente cumprir a ideia da provisoriedade da medida de acolhimento (Supervisor de unidade de acolhimento). 
O relato reforça a ideia de que a família é abordada como incapaz, de que a rede de atendimento tem fragilidades ao não constituir espaços que possam dialogar com as demandas de atendimento dessas famílias. Ao refletir sobre o seu trabalho, o educador declara que se sente "responsável por dar novas perspectivas aos adolescentes que têm problemas e que foram vítimas das próprias famílias, da falta de cuidado, dos desleixos destas e o Estado pegou a guarda deles" (educador social). A fala do educador corrobora, também, a discussão de que a família é tomada de forma despotencializada e culpabilizada.

O trabalho centra-se, não raras vezes, no atendimento às crianças e aos adolescentes dentro das unidades, como exposto a seguir:

Hoje, ainda é muito difícil você encontrar unidades ou entidades conveniadas com o Município que efetivamente trabalhem com a potencialização dessas famílias, dessas crianças acolhidas. Com a possibilidade dessas famílias, que tiveram seus filhos acolhidos, virem a superar os fatores que acabaram fazendo com que elas violassem os direitos de suas crianças para que essas crianças retornem. Então, hoje em dia, a gente tá muito focado em cuidar da criança dentro do abrigo, mas a gente tá pouco focado em cuidar da família pra que essa criança possa voltar (Supervisor de unidade de acolhimento).

Trata-se de uma prática de acolhimento na qual a família recebe pouco investimento para que possa superar as situações que levaram à violação de direitos das crianças e dos adolescentes. Mais uma vez, constata-se, na história da assistência à infância, a institucionalização como forma de intervenção e resolução dos problemas familiares.

O termo é outro, fala-se de acolhimento e não de internação, mas a institucionalização, com o consequente afastamento da família e da vida comunitária, permanece como prática de atendimento. Em outra entrevista, uma gestora da política pública diz:

A gente já teve vários casos de acolhimento indevidos que é de assustar. A gente teve um caso de uma família, vários membros que foram acolhidos por questões de pobreza, com vínculo fortíssimo, os meninos chegaram nas unidades chorando, desesperados (Gestora $\mathrm{PBH})$.

A ressignificação das situações de violência nos contextos familiares, a identificação dos conflitos e a reorganização do grupo familiar são ações a serem desenvolvidas em conjunto com as famílias, visando a estabelecer condições que permitam o retorno das crianças e dos adolescentes ao grupo familiar. No entanto, percebe-se que as dificuldades de conexão entre os diversos equipamentos de Assistência Social, para promover a inclusão das famílias em atividades sociais e 
comunitárias que poderiam potencializar os seus recursos materiais e simbólicos, acabam por definir que a sétima medida protetiva, o acolhimento institucional, com a consequente suspensão temporária do poder familiar, torne-se a primeira medida.

A convivência familiar e comunitária são direitos estabelecidos na legislação, o que faz pensar sobre a ambivalência da medida protetiva de acolhimento institucional que tem como objetivo a proteção de direitos, mas cuja execução implica a violação de direitos. Considerando que a aplicação dessa medida protetiva tem sido tomada como a primeira, em detrimento da aplicação das demais, pode-se dizer que, não raras vezes, crianças e adolescentes têm tido o direito à convivência familiar e comunitária violado.

Embora a política de Assistência Social coloque a família como destinatária de suas ações e a preservação de vínculos conste como um de seus objetivos primários, constata-se uma discrepância entre o prescrito na legislação que regula a política pública e a execução dos serviços que compõem a materialização de tal política. Pode-se dizer que o prescrito na lei não é transposto para a realidade de forma mecânica. Os princípios são investidos de sentidos e transformados em ações que trazem as marcas históricas de atendimento à infância e à adolescência no Brasil, das filiações institucionais das entidades que prestam os serviços de atendimento e dos sentidos compartilhados entre os profissionais e crianças, adolescentes e famílias. A constituição das ações de atendimento se dá, assim, num cenário complexo e dinâmico.

Em decorrência da complexidade do contexto, o necessário trabalho de proteção, em algumas situações, tem de ser desenvolvido com dupla dimensão. Ao falar do trabalho desenvolvido pela entidade, o coordenador de uma casa de acolhimento se expressou da seguinte maneira:

Como que é a realidade? Nossa, aí, eu vou ficar três dias falando aqui. Eu acho que é mais duro mesmo. Porque, quando você tá diante de um papel, de um relato falando de um adolescente, que seus familiares abusam sexualmente, que ele é fruto de uma relação entre pai e filha, isso tudo é uma coisa: ler um documento. Estou te dando um exemplo, outra coisa é você vivenciar isso, você experimentar, ver e trabalhar com aquelas questôes que aquela criança e adolescente te trazem, realmente, e fazer alguma coisa disso. Fazer com que essa questão que, pro menino, naquele momento, não é um trauma não venha a ser, mas também que ele entenda que não é uma coisa saudável, não é uma coisa pra ser lidada como natural (Coordenador de unidade de acolhimento).

Para esse profissional, o acolhimento tem como função problematizar aspectos muitas vezes naturalizados na história das crianças e dos adolescentes acolhidos, no caso a violência sexual. Por outro lado, a intervenção não pode 
parar na dimensão do problema. Ela precisa apresentar alternativas para que o reconhecimento do problema não seja cristalizado em forma de trauma pela criança e pelo adolescente, e resulte numa (re)vitimização constante.

Tal complexidade do atendimento no contexto do acolhimento foi discutida, ainda, por outros profissionais:

Eu percebo que a medida de acolhimento é favorável porque ela tira os meninos da negligência, eles estão sendo resguardados de uma negligência, mas eu tenho as minhas dúvidas da duração desse acolhimento. Porque passa a ser uma naturalização, o que é muito perigoso. Eu tive uns aqui. Um que, quando ele chegou, passaram-se uns três, quatro meses, e ele tava gostando do abrigo. Nós fizemos tantas construçôes com ele pra que ele não gostasse do abrigo, pra que ele "eu quero embora, eu tenho a minha casa", porque o que eu percebo é essa naturalização, por mais que eu idealizo um dia ter alguém, idealizo um dia estar na minha família, eu estou aqui. A minha realidade aqui, pelo visto, como tá acontecendo, tem muito tempo, passa a ser natural (Técnica de unidade de acolhimento).

Aqui a complexidade reside no fato de que a medida protetiva de acolhimento, que é excepcional e provisória, passa a ser vivida, no contexto das unidades de acolhimento, como natural e vai perdendo o seu caráter de excepcionalidade. Situação apresentada também pelo profissional a seguir:

\begin{abstract}
A gente tem hoje um acolhimento que consegue, certamente, garantir que aquela criança esteja protegida, ela tem os recursos mínimos garantidos para sobreviver. As unidades, é [...] apesar de problemas financeiros, há um padrão mínimo em Belo Horizonte bastante relevante, comparado ao nível nacional, em termos de garantir materialmente o acolhimento das crianças. No entanto a função que eu entendo, pelo menos da minha leitura do ECA e tudo é que as unidades de acolhimento institucional, não são orfanatos; elas deveriam cumprir aquela função de não manter aquela criança ali muito bem acolhida e para sempre. Ela deveria cumprir a função de fazer com que ela retornasse a sua família, primeiramente, e para sua comunidade, para a comunidade da qual ela viesse (Supervisor de unidade de acolhimento).
\end{abstract}

$\mathrm{O}$ atendimento das crianças e dos adolescentes nas unidades de acolhimento é necessário, mas não pode se tornar definitivo na vida das crianças e dos adolescentes, até porque, entre os princípios da medida de acolhimento institucional, encontram-se os da excepcionalidade e provisoriedade, o que concorre para a não institucionalização prolongada. As instituições têm o papel de acolher, mas com a perspectiva de que são necessárias ações que permitam o desacolher.

A percepção do preconceito para com os acolhidos é outro sentido do acolhimento institucional expresso nas falas dos profissionais. O preconceito é 
lembrado como um fato que interfere na constituição de ações para atendimento a crianças e adolescentes:

A sociedade entende o acolhimento como o infracional, e isso atrapalha demais, até mesmo para conseguir as coisas. Porque são idades que a sociedade brasileira hoje em dia coloca: "Ah, adolescentes não querem nada com a dureza, adolescentes não assumem responsabilidades, só sabe dos seus direitos, não quer saber de seu dever" (Técnica social, unidade de acolhimento).

Ao se atribuir à medida de acolhimento o sentido de restrição de liberdade, ela perde o significado de protetiva e passa a ser definida pela punição, como diz o educador: "Esse olhar que vocês acham que todo mundo tá olhando pra vocês, com uma seta apontada pra vocês, mostrando que vocês são de abrigo" (Educador social).

Associada a isso, tem-se a concepção de que os adolescentes estão em "situação irregular" e que, como "desviantes" da norma social, devem ser punidos. Estar numa instituição de acolhimento passa, então, a ser vivido como situação constrangedora, principalmente pelos adolescentes.

\section{CONSIDERAÇÕES FINAIS}

O acolhimento institucional prescrito pelos ordenamentos jurídicos e pela política pública visa à restauração de direitos e à inclusão social e comunitária das crianças e dos adolescentes. $\mathrm{O}$ acolhimento institucional deve ainda contribuir para a restauração dos vínculos familiares bem como para a elaboração subjetiva das vivências das crianças e dos adolescentes, potencializando-os para que possam assumir novas posições como cidadãos e pessoas capazes de desenvolver relações afetivas e comprometidas com o bem viver não somente pessoal, mas de todos aqueles com os quais se relacionam.

Embora uma medida tomada em contextos e situações que envolvem intensos sofrimentos das crianças, dos adolescentes e de suas famílias, ela pode tornar-se uma experiência positiva na vida de todos os envolvidos, pois pode potencializar os recursos materiais e simbólicos das famílias e contribuir para a superação das dificuldades.

No entanto a construção das ações que buscam a autonomia e a exploração do potencial da medida protetiva para a reorganização das relações e do contexto familiar tem encontrado limites nas fragilidades de conexão dos diversos equipamentos que compõem o sistema de garantia de direitos, bem como nas fragilidades subjetivas e de formação profissional dos diversos agentes responsáveis pelo cotidiano da realização da medida protetiva de acolhimento institucional. 
O que deveria ser o objetivo primeiro da medida, a preservação de direitos, é confrontado com a pouca perspectiva de mudança dos contextos comunitário e familiar e com o baixo investimento para superação das complexidades, seja por parte dos profissionais, que se reconhecem como limitados diante da fragilidade das açôes realizadas nos diversos equipamentos jurídicos e sociais, seja por parte das famílias, despotencializadas material e simbolicamente.

O desenvolvimento da política pública de proteção social destinada às crianças e aos adolescentes, na chamada era da proteção integral, estabelecida a partir da promulgação do Estatuto da Criança e do Adolescente (Lei n.o 8.069, 1990), é um exercício de negociação constante entre todos os equipamentos e operadores responsáveis pelo trabalho cotidiano. É também um esforço de reflexão crítica constante para que se possa, de fato, superar a concepção de crianças e adolescentes pobres como "menores em situação irregular", e apropriar-se da concepção de que crianças e adolescentes são sujeitos de direitos e sujeitos ativos, que devem ser escutados e considerados em suas demandas.

$\mathrm{O}$ estudo das narrativas que emergem dos documentos e das entrevistas apontou que as ações de atendimento são constituídas em um cenário complexo e dinâmico, em que crianças, adolescentes e suas famílias são investidos de sentidos pelos trabalhadores. Sentidos que nem sempre levam à compreensão de quem são essas pessoas, como vivem, quais suas demandas, dificuldades e potencialidades.

As narrativas apontaram que a política de proteção às crianças e aos adolescentes é tecida com base nos elementos prescritos nas normativas oficiais e também dos elementos dissonantes entre a imagem idealizada das famílias, das crianças e dos adolescentes em relação às condições concretas de vida dessas famílias, ou seja, a família que se imagina não é a família com a qual se vive.

A dimensão universal dos direitos e dos sujeitos portadores desses direitos, presente nos documentos oficiais, é ressignificada na dimensão particular, vivida no cotidiano dos serviços, onde se fazem adequações e adaptações dos elementos contidos na legislação e nos ordenamentos da política pública. As dimensões universal e particular da medida de acolhimento institucional são também ressignificadas e reelaboradas na dimensão subjetiva e singular de todos os envolvidos. Nessa interação dialética entre as dimensões universal, particular e singular, as narrativas e os sentidos para a prática do acolhimento institucional são construídos cotidianamente. 


\section{REFERÊNCIAS}

Brasil. (2006). Ministério do Desenvolvimento Social e Combate à Fome. Plano Nacional de Promoção, Proteção e Defesa do Direito de Crianças e Adolescentes à Convivência Familiar e Comunitária. Brasília: MDS, Conselho Nacional de Assistência Social.

Cellard, A. (2010). A análise documental. In J. Poupart, J.P. Deslauriers, L.H. Groulx, A. Laperriere, R. Mayer, A.P. Pires. (Orgs.), A pesquisa qualitativa: enfoques epistemológicos e metodológicos. (Vol. 295, pp. 2010-2013). Petrópolis: Vozes.

Decreto n. ${ }^{\circ}$ 17.943-A, de 12 de outubro de 1927. (1927, 12 de outubro). Consolida as leis de assistência e proteção a menores. Coleção de Leis Brasileiras. Recuperado a partir de hhttp://www.planalto.gov.br/ccivil_03/ decreto/1910-1929/d17943a.htm

Gergen, K. J. (2009). O movimento do construcionismo social na psicologia moderna. Revista Internacional Interdisciplinar INTERthesis, 6(1), 299-325. Recuperado a partir de https://periodicos.ufsc.br/index.php/interthesis/article/ view/1807-1384.2009v6n1 p299/10807. (Publicado originalmente em 1985).

Gergen, K. J. \& Gergen, M. (2010). Construcionismo social: um convite ao diálogo. Rio de Janeiro: Instituto Noos.

Iñiguez, L. (2002). Construcionismo social e Psicologia social. In J. B. Martins, D. E. Hammouti \& L. Iñiguez (Orgs.), Temas em análise institucional e em construcionismo social. (pp. 127-156). São Carlos: RiMA, Curitiba: Fundação Araucária.

Lei n. ${ }^{0}$ 6.697, de 10 de outubro de 1979 (1979, 11 outubro). Institui o Código de Menores. Diário Oficial da União, Brasília. Recuperado a partir de http:// www.planalto.gov.br/ccivil_03/leis/1970-1979/L6697.htm

Lei n. ${ }^{\circ}$ 8.069, de 13 de julho de 1990 (1990, 16 julho). Dispõe sobre o Estatuto da Criança e do Adolescente. Diário Oficial da União, Brasília. Recuperado a partir de http://www.planalto.gov.br/ccivil_03/leis/L8069.htm

Lei n. ${ }^{\circ}$ 12.010, de 3 de agosto de 2009 (2009, 4 agosto). Dispõe sobre adoção; altera as Leis n. ${ }^{\text {ss }} 8.069$, de 13 de julho de 1990 - Estatuto da Criança e do Adolescente, 8.560, de 29 de dezembro de 1992; revoga dispositivos da Lei n. ${ }^{\circ}$ 10.406, de 10 de janeiro de 2002 - Código Civil, e da Consolidação das Leis do Trabalho - CLT, aprovada pelo Decreto-Lei no 5.452, de $1 .^{\circ}$ de maio de 
1943; e dá outras providências. Diário Oficial da União, Brasília. Recuperado a partir de http://www.planalto.gov.br/ccivil_03/_ato2007-2010/2009/lei/ 112010.htm

Mello, R. P. (2002). Do estranhamento à familiaridade: estratégias e contradiçôes na construção da noção de abuso sexual infantil intrafamiliar. (Tese de Doutorado). Pontifícia Universidade Católica de São Paulo, Programa de Estudos Pósgraduados em Psicologia Social, São Paulo. Recuperado a partir de https:// tede2.pucsp.br/handle/handle/16929

Minayo, M. C. S. (2005). Introdução. In M. C. S. Minayo, S. G. Assis \& E. R. Souza (Orgs.), Avaliação por triangulação de métodos: abordagem de programas sociais. (pp. 19-52). Rio de Janeiro: Fiocruz.

Rizzini, I. \& Rizzini, I. (2004). A institucionalização de crianças no Brasil: percurso histórico e desafios do presente. Rio de Janeiro: Ed. PUC Rio, São Paulo: Loyola.

Spink, M. J. (2013). Práticas discursivas e produção de sentidos no cotidiano: aproximações teóricas e metodológicas. São Paulo: Cortez. 